\title{
Politics as an Appearance and Reality Show: The Hermeneutics of Suspicion
}

\author{
Michael Billig
}

Public opinion polls show politicians to be among the least trusted professionals in contemporary Britain. Regardless of the precise questions asked, a fairly consistent pattern of distrust has been revealed in the past few years. For example, a MORI poll, conducted in July 2003, found 75\% of the adult population claimed to distrust politicians (www.mori.com/ polls/2003). According to the British Social Attitudes Survey of 2001 only $11 \%$ of the population said they trusted politicians to tell the truth most of the time (Bromley et al., 2001). An ICM poll, conducted in March 2005, just before the General Election, revealed that $87 \%$ of respondents believed that politicians did not keep their promises, while 92\% said that politicians never gave 'a straight answer'. Also, 73\% of respondents said politicians had shown themselves to be dishonest too often. This is not merely happening in Britain. A Gallup International Poll revealed that across the world politicians were the least trusted professional group (reported in Guardian, 2005, 15 September). Two other results from the 2003 MORI poll are worth noting. Journalists were equally as distrusted as politicians, but $66 \%$ said they would trust newsreaders. If the distrust of politicians is widespread, then one can ask how this belief is reproduced. In a mass society, in which people have little direct personal contact with politicians, people are liable to receive their information about politicians via the media. In this context the trust of newsreaders is highly suggestive, for newsreaders may represent a trusted source of information about politicians' untrustworthiness.

The present investigation looks at this issue in relation to the General Election campaign. There are two preliminary considerations. First, if the distrust of politicians is part of contemporary common sense, as indicated regularly by the polling data, then it will not be dependent on the actions of a particular politician or party. It is possible that this distrust might be 
in-built into the frameworks for presenting politics in the media. If so, it should be evident at the beginning of the General Election coverage, rather than being a reaction to the conduct of the campaign. Secondly, if there is a widespread suspicion of politics, then this should not be confined to the dramatic media moments, when, for instance, a famously pugnacious interviewer successfully challenges the veracity of a politician. It should be reproduced within, and reinforced by, the more banal moments of political coverage.

As compared with the 1970s, television news nowadays presents shorter extracts of politicians speaking, segmenting these extracts between presenters' comments and interpretations (Hallin, 1972; see also the discussion of 'soundbite culture' of modern British Elections in Deacon et al., 2005). To use the terminology of Roland Barthes (1977), the televised images of politician are 'anchored' in the words of the presenters. The question is whether such anchoring routinely reproduces what Paul Ricoeur (1970), in another context, termed 'the hermeneutics of suspicion'. Ricoeur was suggesting that psychoanalytic theory encourages suspiciousness as the means understanding. The psychoanalyst distrusts what the people say about their reasons for their actions, but treats their words as providing clues about unexpressed motives. One might ask whether an analogous suspicion routinely occurs in relation to the televised words of politicians. This would mean that politics is routinely depicted in such a way that what the politicians say about themselves and their political motives are presented in ways that encourage suspicion. To investigate this,

As has been often remarked, television provides the most important source of political information about politics. In a recent critique of political journalism, especially broadcast journalism, John Lloyd has claimed that politicians are routinely invited to appear on television on increasingly harsh terms (Lloyd, 2005). Therefore, the focus will be on routine episodes in the television presentation of the British General Election of 2005 to see whether there was a general hermeneutics of distrust, such that when the words of politicians are presented they are being routinely anchored to a discourse of suspicion that encourages recipients to search for unexpressed, hidden motives. In order to substantiate such a thesis, and to investigate whether there is a regular culture of political suspicion, it is not sufficient to analyse the dramatic confrontations between politicians and interviewers that themselves sometimes become news items. It is necessary to examine the routine, unexceptional modes of presentation to see whether politics is being presented in ways that assume a culture of political suspiciousness. This means analysing the routine ways that politics 
is being presented, paying attention to the discursive details, for often small, banal words play a big role in the reproduction of ideology (Billig, 1995; van Dijk, 1998).

\section{Strategic interpretation}

The first week of the Election campaign saw the political parties launching their Election manifestoes and the television channels launching their coverage of the campaign. In some respects there were parallels between the two sorts of launchings. In the case of the Conservative manifesto and ITN news there was a simultaneous launching on the evening news of 12 April.

The ITN coverage of the Conservatives' manifesto followed a conventional pattern. The story was introduced by the main newsreader, Trevor Macdonald. His announcement contained an implicit interpretation: 'There weren't many surprises although Mr Howard did promise to have more police on the streets, better school discipline, stricter controls on immigration, and lower taxes.' Then Macdonald handed over to Nick Robinson, ITN's political editor. Robinson's commentary was interspersed with clips of the Conservative leader Michael Howard speaking at the press conference held earlier in the day. Howard could be heard declaiming about 'the sunshine of hope breaking through the clouds of disappointment'. Robinson commented:

'The rhetoric may be soaring but the promises are now familiar and the manifesto slim. That's because it has one simple purpose (.) to channel anger with Tony Blair into votes for the Tories.' ${ }^{1}$

In a general sense, the presenter was offering guidance for interpretation, thereby mediating those images of Howard speaking that the television producers had selected to show. In this instance, the guidance assumed a distinction between the manifest scene that was being shown and its latent, unheard meaning. The viewers might hear the soaring rhetoric and see the slimness of the manifesto but there was something more that the outward pictures and words did not reveal.

In this case, as in many others, the extra element is the strategic purposes of the politician. The presenter offers a 'strategic interpretation', telling the audience that the politician has a reason for speaking in the way that can be seen and heard. A strategic interpretation, such as that provided by Robinson, assumes a distinction between appearance and reality. All viewers can see what the politician is doing/saying: but the why is not 
apparent. Robinson was claiming that behind the manifest scene lies 'one simple purpose'. If this is presumed non-obvious to the viewer, then expert knowledge is required for this behind-the-scene understanding.

According to discourse analysts, the suggestion of an underlying purpose, or 'stake', typically functions to throw doubt on, or to discount, another speaker's version of events (Potter and Edwards, 1990; Edwards and Potter, 1993; Potter, 1996). Robinson's own use of the term 'rhetoric' in this context is not accidental. In popular use, the word 'rhetoric' frequently contains an element of criticism, as 'mere rhetoric' is contrasted, implicitly or explicitly, with substance (Billig, 1996). By saying that there is something behind the 'soaring' words of Howard, Robinson was inviting viewers to treat those words with caution. The strategic interpretation, that is so common in television reporting, represents a rhetorical form that belongs to the hermeneutics of suspicion. In effect, it is saying 'beware of the outward words, for they reflect of an inner, hidden purpose'.

\section{Introducing unspun}

After the report on the launching of the Conservatives' manifesto, the ITN evening news of April 12 introduced its own special Election feature Unspun. Macdonald announced:

'Throughout the campaign we'll be attempting to help you to separate fact from fiction. We'll be analysing the policies of the parties to try to help tell the difference between spin and substance. To do that we've recruited a panel of insiders and experts and we begin tonight with one of the main promises of Mr Howard's Conservative manifesto (.) controlling immigration. Tom Bradby reports on the Conservatives' immigration claims (.) unspun'

Tom Bradby began his report, standing against a backdrop of faces: 'Trevor, this is the Unspun studio and these are the faces of the insiders and experts who are going to be helping us to get to the truth and unspin the rhetoric during this Election campaign; they are leaders in their fields be it the economy, health, security, terrorism or as tonight immigration.'

Bradby, then, reported on the Conservatives' figures about immigration, calling on experts to give assessments. He posed a question that calls for a strategic answer: 'So why does Mr Howard want to make immigration such an issue?' This was followed by graphics of the word UNSPUN revolving, and then a shot of Mr Howard shaking hands with people in a crowd. Bradby answered his own question over the pictures: 'One answer according 
to a former Tory spin doctor is that it resonates strongly with working class voters.' Bradby concluded his report: 'Tomorrow I'll be back with our insiders and experts to unspin (.) the next big issue (.) Trevor.'

The format had been planned well in advance. 'Unspun' was being introduced as a special feature that would remain running throughout the Election coverage. . The slot had its own narrative presupposition. The aim was to separate 'fact from fiction', or 'spin' from 'substance'. The implication was that politicians create fiction, spin and appearance. Special experts would be required to show the reality - including the strategic reality - behind appearances. The presupposition of politicians' untrustworthiness was being taken for granted. Like most commonplace beliefs it was not presented as standing need of justification (Billig, 1996).

The same news bulletin introduced another feature that was to become a regular item during the campaign: 'The Body Politic'. Macdonald explained: 'We've recruited the country's top body language analyst (.) Professor Geoffrey Beattie from Manchester University to help us assess what hidden messages the politicians are sending.' In his first report, Professor Beattie claimed that politicians rarely revealed their aggressive impulses in public but such impulses 'are unconsciously channelled into hand gestures revealing their true:: feelings'. Such claims, regardless of their validity, are interesting because they provide further evidence of the distinction between appearance and reality. Again, an expert was claiming to reveal the reality behind the potentially misleading impressions produced by politicians.

Here we can see the hermeneutics of suspicion becoming institutionalised as a guiding principle. The mode is pre-emptive, not reactive. The experts are not summoned because a particular politician has uttered a remark that needs to be treated with suspicion. The experts are continually on hand because 'everyone' knows that the politicians routinely say things, create appearances and even make gestures in ways that conceal underlying realities.

\section{Appearance and reality}

The distinction between political appearance and underlying reality was a widely used trope on all the main news channels in the coverage of the Election. The trope could be heard on the BBC 10 o'clock news on the same evening when the Conservative manifesto was launched. The presenter Hugh Edwards called on 'our economics editor' in order 'to try to establish whether the Tory plans stand up to scrutiny'. 
The editor, Evan Davis, began by mentioning the incomprehensible talk of billions and squillions from Gordon Brown today rubbishing Oliver Letwin's spending plans'. The folksy tone (as represented by 'billions and squillions') seems to suggest that Davis is identifying with the audience's presumed incomprehension. But the overall narrative is conveying that the talk can be made comprehensible, as a series of experts explain the apparently incomprehensible. The experts are sceptical of the party's claims to be able to save money by cutting waste. Davis concludes:

'The most dubious claims are actually the ones the parties agree on, they all say they'll save billions of pounds ... if you ignore all the pledges to cut waste from Mr Brown and Mr Letwin, you're left with one shining nugget of truth in the river of mud that has flowed today, and that is we can expect the Conservatives to spend (.) and tax a little less than Labour (.) Hugh'

Again the words of the politicians were being contrasted with words of truth.

Television political presenters and interviewers must be above party partisanship. They use a variety of rhetorical formats to display neutrality, for example attributing judgements, which could be understood as favouring one party over another, to independent sources (Clayman and Heritage, 2002). In this case, the economics editor is careful not to claim that the nugget of truth lies on one side or the other. The rival claims are equally dubious. The word 'actually' is suggestive. What the parties agree upon is actually - really - the most dubious claim of all. In this way, the editor avoids appearing biased by throwing doubt on all parties equally. There is an implicit claim. In contrast to the dubious judgments of politicians, the judgment of the editor about such judgments is not open to doubt. His claims match what 'actually' is the case as he excavates the nugget of truth that the politicians cover with their self-interested rhetorical mud.

Sometimes the rhetorical trope of appearance and reality was not applied to the claims of politicians but to their visual images, as in the case of the Body Politic. Then the news programmes would use experts to employ the hermeneutics of suspicion to the very images that the news programme was presenting. Viewers would be shown visual images but then warned not to trust the apparent straightforwardness of the pictures. On May 3 Shaun Ley reported on BBC News that the party leaders were concentrating their efforts on marginal seats. His report showed shots of Blair and Brown on the campaign trail, walking in a car park. Blair was seen to buy two ice creams. He then offered one to 
Gordon Brown saying amid laughter 'Here Gordon, not often a chance to get something free.' At this point Shaun Ley's voice-over continued:

'It may look relaxed but every aspect of this last few days of campaigning is carefully calculated by the parties [close-up of ice-cream in Blair's left hand, as he signs an autograph with his right; more background guffaws] Labour's fear underlined by the latest opinion polls is that the lead it appears to have nationally [shot of Blair smiling] could in the seats that matter simply melt away' [Blair bites into the ice-cream]

The rhetorical format 'it may look ... but ...' conveys suspicion. The format, when used in a voice-over, deictically points to the images that are being shown. The 'but' warns that 'things are not as they seem': the appearances deceive. The viewers might think the scene depicts two relaxed figures, joking about an ice-cream, but they would be naïve to accept the images at face-value. 'Every aspect', it is said, has been 'carefully calculated'. Thus, the relaxed images are being interpreted as anything but relaxed and spontaneous. Appearances are deceptive, so the interpretation warns.

In this way, the voice-over anchors the scene in the hermeneutics of suspicion. The ice-cream is not just an ice-cream; the joke is not just a joke. They are strategic calculations that would have remained hidden from the innocent viewer but for the expertise of the expert.

\section{Promoting the expert}

In the trope of misleading appearances and underlying strategic reality the role of the expert is crucial. The expert is presented as the trusted guide in the territory of misleading appearances, enabling the viewers to discover the nuggets of truth. In contrast with the politicians, the experts are presented as credible figures whose judgements are to be trusted. Accordingly, the television programmes promote the skills of their experts. When ITN introduced 'Unspun', the people who were going to help 'get to the truth' were 'experts and insiders' who were 'leaders in their fields'. Trevor Macdonald described the Body Politic's expert as 'the country's top body language analyst', emphasising his professorial status. In this way the credentials of expertise are routinely advertised.

The difference between the presentation of experts and politicians can be seen in the respective ways that interviewers treat them. In the earlier days of television interviews, interviewers tended to play 'pat-ball' with politicians, feeding them with open topic-questions and offering them 'respectful prompters' (Clayman and Heritage, 2002). Today, the successful 
political interviewer is expected to subject politicians to adversarial interviews, in which interviewers use a variety of hostile question-formats (Clayman, 2002; Clayman and Heritage, 2002; Heritage, 2002). For example, interviewers frequently use 'negative interrogations' or 'negative tag questions' which are seen as challenging what politicians say. Interviewers often pose quandary questions, inviting politicians to agree with one of two alternative answers in the knowledge that both answers are equally damaging to the interviewee's credibility (Bull, 1998, 2002; Bull et al., 1996). Interviewers justify this aggressive approach by claiming that politicians typically conceal matters from the public. Jeremy Paxman reportedly claims that, when interviewing politicians, it is a sound principle to ask oneself 'Why is this lying bastard lying to me' (Clayman and Heritage, 2002, quoted p. 31). ${ }^{2}$

When interviewers talk to the experts the setting may physically resemble the political interview. The interviewer might use the same studio for questioning politicians and experts. The interviewer may use the same conventional beginnings and endings to open and close the sequence of questioning (Clayman and Heritage, 2002, ch. 3). But in between the questions have a very different design. Interviewers use few of the adversarial question-formats when talking with experts. Instead, there are the straightforward 'pat-ball' types of question that cue the interviewee to a broad topic without adversarial follow-up.

A particularly striking type of this gentle interviewing occurred on Newsnight April 14, when Jeremy Paxman, famed as the fiercest of all television interviewers, played pat-ball with Frank Luntz. The latter was introduced as the American pollster who advised on Republican campaigns in the United States. Paxman's introduction did not mention that Luntz was a controversial figure in his own right and that in the United States professional colleagues have called into question his data and interpretations. ${ }^{3}$ In this way, the hermeneutics of suspicion was not extended to the expert who was there to show how to read the messages of politicians to uncover their underlying strategic meaning.

Luntz's answers to Paxman's questions offered strategic interpretations for what the words and actions of politicians. Paxman's 'questions' were, in the main part, not questions in grammatical form but pointers to the topic that Luntz should talk about next:

Paxman: err, now let's start with the Lib Dems they launched their manifesto today.

Luntz: well the two words that you're going to hear from them constantly positive and fair ... 
Luntz talked about the Liberal Democrats use of the word 'hidden' and the strategic purpose of the word. Paxman's supplementary question does not challenge Luntz's prediction or knowledge. He merely asks 'Could it work?' inviting Luntz to speculate expertly on the potential efficacy of the Liberal Democrats' rhetorical strategy. And then it is on to the next party: 'Ok what about Labour' and Luntz then talks about Blair and how he is attempting to appear non-ideological. Paxman then raises the topic of Gordon Brown, again with a statement not a grammatical question: 'Now Brown, he's obviously been playing a much bigger part than expected.' Luntz interprets this not as an opinion offered by Paxman but as cue to talk about Brown's rhetoric.

After that Paxman feeds the next topic: 'Now as far as the Conservatives are concerned.' Luntz interprets this, not as a preface for remarks that Paxman might make, but as a cue for his own analysis of the Conservatives' rhetoric. After Luntz has spoken about the Conservatives, Paxman responds with a tag question 'It's turning out to be quite an interesting Election isn't it?' This question is not the sort of negative tag, which challenges the interviewee. Instead the assertion is a coded compliment: Luntz's analyses have demonstrated how interesting the Election is becoming, haven't they?

Throughout the exchange there were no probing or adversarial questions. The pat-ball type of questioning represents a pseudo-interview, in which interviewees are not questioned so much as invited to demonstrate their expertise within a conversational format. In the Paxman-Luntz interview, it was the interviewee, not the interviewer, who controlled the presentation of clips of illustrative film showing politicians using particular pieces of rhetoric.

The pat-ball format reflects the way that the appearance-reality trope is presented on television. With a hidden reality to be exposed, the news programmes have an interest in promoting their experts. Consequently, they might be described as leaders in their field, top experts etc. The news presenters may find themselves using phrases that come close to the language of advertising. Even experts like Luntz, who in the past have worked for a particular political party, are now presented as unmotivated 'insiders'. When questioned, they are treated with old-fashioned deference.

\section{Challenging the expert}

Occasionally a politician will challenge the judgements of an expert with interesting results. An example occurred on BBC's Newsnight on April 6 just before the official announcement of the Election but at a time 
when the unofficial campaigning had begun. Again Jeremy Paxman was involved.

Three politicians had been invited for a discussion of the economy with Paxman: David Miliband (a Labour minister), David Willetts (Conservative) and Vince Cable (Liberal Democrat). Sitting next to Paxman on one sofa and opposite the politicians was the BBC's economic correspondent, Stephanie Flanders. Paxman introduced her, mentioning her expertise and giving her a feed question to display her expert judgment: 'Well we'll be talking to the politicians err in a moment but first Newsnight's economic guru Stephanie Flanders [turning to Flanders] how good has the economy been and do you think Gordon Brown deserves the credit for it?' Flanders, in the course of her answer commented on the 'small difference' between the two parties in relation to cuts in public spending.

Then Paxman questioned the politicians in turn. He started with Miliband. The questioning was typically adversarial. Paxman used what analysts have called an 'avoidance-avoidance' questions (Bavelas, 1998; Bull, 2002). This sort of questions seems semantically to call for a yes/no answer, but either 'yes' or 'no' would be equally disastrous for the politician. Politicians, faced with avoidance-avoidance questions, appear to equivocate, for they cannot deliver the simple 'yes' or 'no' answer. Labour's honesty was immediately questioned:

Paxman: Err David Miliband, you came from a meeting tonight in which the manifesto was apparently finalized signed off on. Is it going to be any more honest about err tax plans than the last one? Miliband: Well the government has lived up to all of its commitments Paxman: ah come on you said last time you wouldn't raise income tax instead of which you raised taxes on income

Miliband starts to answer and Paxman begins to interrupt. It is in this sequence that Miliband criticises Flanders's assertion about there being only a small difference between the parties:

Miliband: just let me finish this (.) a low debt high employment economy does not come about by accident. A low debt unem- high un- high employment economy comes about because of economic political choices that are made and Stephanie [noise from Paxman as if trying to interrupt] for Stephanie to say for Stephanie to say that the differences between the parties are not significant is completely false if $=$ Paxman:= Are you questioning her judgement? [using a tone that conveys incredularity] 
Miliband: I certainly am because I think that [shot of Flanders] a commitment on the part of the Conservatives= Paxman:=you're a brave chap

Miliband: a commitment on the part of the Conservatives [Paxman: right] to say that we should reduce the share of national income that's spent by the state ... and I don't think we should minimize that I think it's a very significant difference . . .

The exchange deserves more detailed analysis than can be given here, but several points can be noted.

Paxman, who routinely challenges politicians' judgement and honesty, did not let the challenge to the BBC's expert pass unquestioned. The challenge was not about facts or figures. Paxman characterised it as a disagreement with Flanders's 'judgment'. He succeeded in interrupting the minister before the latter had not given the reasons for disagreeing with the BBC guru. Paxman, in consequence, was not questioning the particular basis for the disagreement in question but the very act of disagreeing with the expert's judgment.

Paxman's challenge took the form of an adversarial question that seemed to imply that questioning the judgement of the expert was something unusual and had to be accounted for. The design of his question and its tone possessed what conversation analysts would term a structural preference for agreement (Pomerantz, 1984; Clayman and Heritage, 2002). When questions have a preference structure, the 'preferred' sort of answer can be supplied without justification, typically by a simple assent. By contrast, the 'dispreferred' answer needs to be justified: the recipient will need to do more than merely dissent from the assertion embedded in the question.

Paxman's tone implied that 'surely you are not questioning her judgement, are you?' Such a question invites a denial that would show agreement with the embedded presupposition: namely Flanders's judgement is not to be questioned. Miliband gives the dispreferred answer. He emphasises his answer - 'I certainly am' - rather than replying simply 'yes'. He then justifies his non-acceptance of Flanders's judgment: 'because I think that ...' Both the emphasised negative and the justification are features of 'dispreferred' answers.

Paxman's question indicated that Miliband was doing something unusual when he challenged the expert's judgment. Acceptance of expert judgment would have needed no special justification. Nor under normal circumstances would it provoke a challenging interruption from the interviewer. Paxman, having received confirmation that the politician was 
indeed challenging the judgment, then tries to interpose what can be heard as a jokey man-to-man aside - 'you're a brave chap'. It is implied, but of course not stated, that the unchallengeable status of Flanders might lie with her gender - only a brave man would challenge a powerful female guru. Miliband ignores this aside. Paxman drops the matter at this point.

However, Paxman does not let the issue remain dropped. Later in the interview Miliband refers to the cost of some government spending without giving precise figures. He says to Paxman: 'Stephanie will give you the decimal points.' Paxman intervenes with a challenging statement, as if exposing the minister of a contradiction: 'Now you respect her judgment apparently.' Unusually for an interviewer Paxman is making an assertion rather than posing a question (Clayman and Heritage, 2002). His assertion is making a rhetorical point. It refers back to the previous exchange, and is designed to resurrect the status of the previously challenged expert in the eyes of the viewer. Now you respect her judgment, Paxman is saying.

The implication is that if Miliband now respects her judgement, then surely he should have accepted it previously. It should be noted that again Paxman poses the issue as one of accepting/respecting the expert's judgment in general - not her judgment on a particular issue. The implication is that if her expert status is accepted - if she is the 'guru' that she was presented as being - then everyone, including government ministers, should defer to her judgement, whatever that judgment may be.

Miliband does not let Paxman's second challenge pass. He extracts himself from the quandary of seeming to respect her judgment at one point but not at another. He says that he respects the judgement of the Treasury which has provided Stephanie Flanders with the figures; and that as a Treasury minister it would be absurd for him not to do so. Paxman laughs. It was a rhetorically skilful escape.

The sequence may have ended with humour, but it illustrates something serious. The interviewer's adversarial questioning is directed against the politician, not the expert. In a matter of judgement, the expert is presented as the person to be deferred to while the politician is the one to be distrusted. If the politician challenges this, then surprise is expressed and the politician is forced into a justification. The common-sense assumption is revealed: how can a politician - someone who has just been marked as a figure of dubious honesty - question the judgment of the media's own expert?

\section{Concluding remarks}

Much more analysis would be required in order to show how the hermeneutics of suspicion was reproduced in its detail by the television 
news coverage of the Election. Even so, a preliminary analysis reveals some interesting features. The suspicion of politicians is in-built into the formats and rhetorical conventions of reporting. One conventional trope in this reporting is the distinction between political appearance and underlying reality. The trope requires a distinction between untrustworthy, biased politicians and trustworthy, unbiased experts. The latter are required to reveal, or to unspin, the misleading appearances of the former.

Of course, modern political parties do use sophisticated techniques to promote their own messages. Techniques of advertising are employed to 'sell' the message and to project the desired images. But there is a danger in seeing the presentation of politics as being a one-way business in which all the manipulation and self-interested rhetoric comes from the politicians, while the media are unbiased seekers of objective truth.

The media have their own interests. The presentation of experts and their demonstration of expertise cannot be free of rhetoric. The news programmes use their own promotional rhetoric. Experts are 'leading' experts; they are gurus whose judgement should be accepted. When Trevor Macdonald and his reporter introduced ITN's new 'Unspun' feature, they used the word 'unspun' several times. The word was flashed on the screen graphically. As in an advertisement, the product was being named being repeatedly, as its reliability and trustworthiness were being proclaimed.

The rhetorical decoding and unspinning is directed against the parties who are competing in the electoral contest. The hermeneutics of distrust stops short as news presenters and chosen experts are presented as being above suspicion. The experts do not need to seek votes. Their words do not require decoding: their appearances conceal no hidden realities. There is no conscious strategy here - just routine conventions that are so familiar that they appear natural. This is how the hermeneutics of political distrust and the promotion of media trustworthiness are routinely reproduced.

\section{Notes}

1. The transcription symbols used here and in other extracts are explained in the Appendix.

2. This quotation is also cited by Lloyd, 2005, in his critique of the hostile style practised by interviewers such as Paxman and John Humphrys.

3. On this see http://dir.salon.com/story/politics/feature/2000/05/26/luntz/ index.xml. 


\section{References}

Barthes, R. (1977). Image-Music-Text. London: Flamingo.

Bavelas, J.B. (1998). 'Theoretical and methodological principles of the equivocation project'. Journal of Language and Social Psychology, 17, 183-99.

Billig, M. (1995). Banal Nationalism. London: Sage.

Billig, M. (1996). Arguing and Thinking. Cambridge: Cambridge University Press. Bromley, C., Curtice, J. and Seyd, B. (2001). 'Political engagement, trust and constitutional reform'. In British Social Attitudes: the 18th Report. London: Sage.

Bull, P.E. (1998). 'Equivocation theory and news interviews'. Journal of Language and Social Psychology, 13, 115-31.

Bull, P.E. (2002). Communication Under the Microscope. Hove: Routledge.

Bull, P.E., Elliott, J., Palmer, D. and Walker, L. (1996). 'Why politicians are threefaced: the face model of political interviews'. British Journal of Social Psychology, $35,267-84$.

Clayman, S. (2002). 'Tribune of the people'. Media, Culture and Society, 24, 191-210.

Clayman, S. and Heritage, J. (2002). The News Interview. Cambridge: Cambridge University Press.

Deacon, D., Wring, D. et al. (2005). Analysis of UK General Election News Coverage. London: Electoral Commission.

Edwards, D. and Potter, J. (1993). Discursive Psychology. London: Sage.

Hallin, D.C. (1992). We Keep America on Top of the World. London: Routledge.

Heritage, J. (2002). 'The limits of questioning: negative interrogations and hostile question content'. Journal of Pragmatics, 34, 1427-46.

Lloyd, J. (2005). What the Media Are Doing to Our Politics. London: Constable and Robinson.

Pomerantz, A. (1984). 'Agreeing and disagreeing with assessments: some features of preferred/dispreferred turn shapes'. In J.M. Atkinson and J. Heritage (eds), Structures of Social Action. Cambridge: Cambridge University Press.

Potter, J. (1996). Representing Reality. London: Sage.

Potter, J. and Edwards, D. (1990). 'Nigel Lawson's tent: discourse analysis, attribution theory and the social psychology of fact'. European Journal of Social Psychology, 20, 405-24.

Ricoeur, P. (1970). Freud and Philosophy. New Haven: Yale University Press.

van Dijk, T.A. (1998). Ideology. London: Sage. 


\section{Appendix}

\section{Transcription Notation}

Based on Potter and Wetherell's (1987) simplified version of conversation analysis).

Underlining increased loudness or a speaker stressing a particular word or phrase.

(.) noticeable short pause

$=\quad$ one speaker's turn is being followed immediately by another speaker's

$:: \quad$ the elongation of the preceding vowel sound

[] information about what is being said or shown is in square brackets.

... material is omitted 
02300_01300_22_cha20.qxp 12/30/2006 5.12 PM Page 238

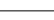

7 Page 238
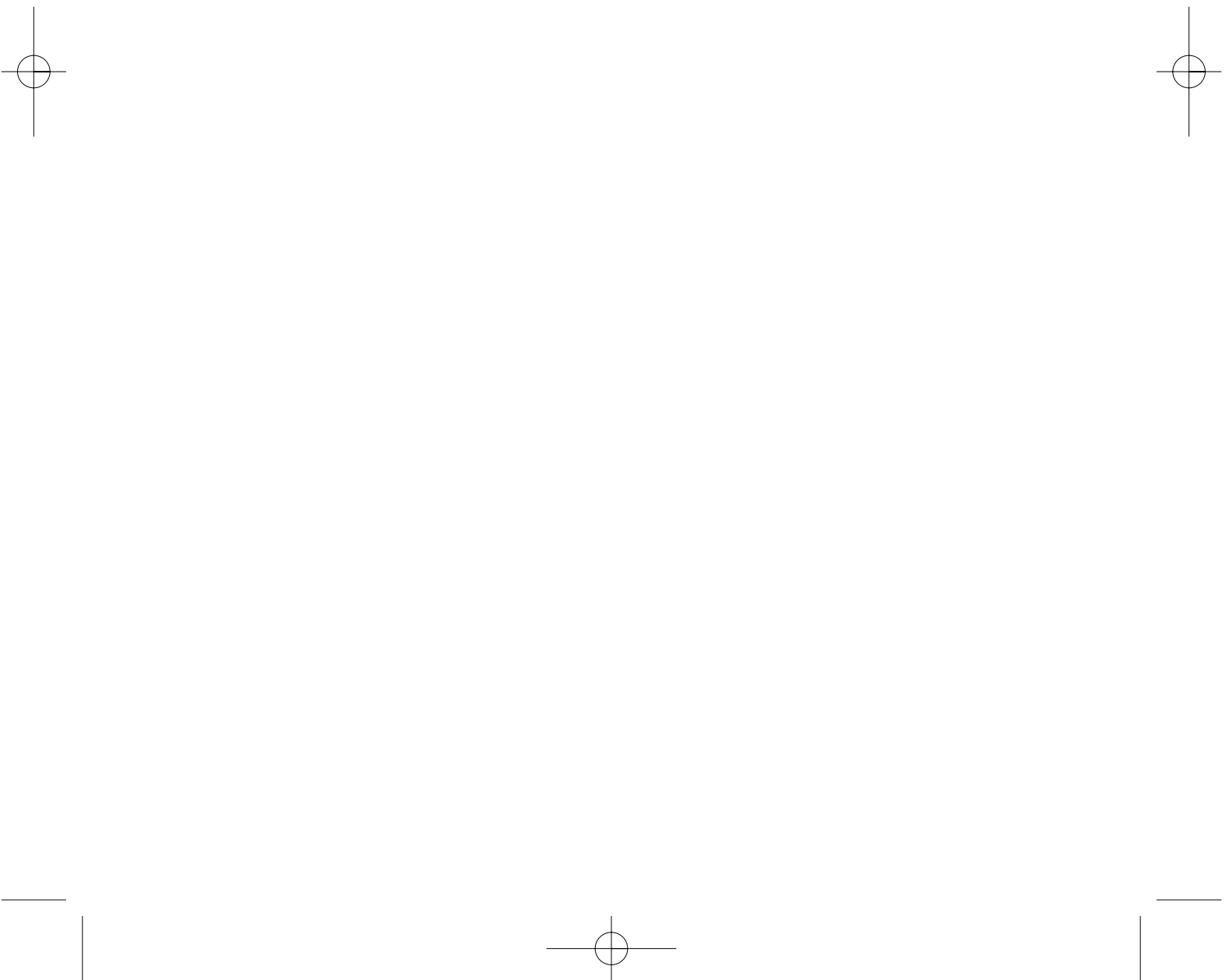